LOGIC, ALGEBRA, AND COMPUTER SCIENCE

BANACH CENTER PUBLICATIONS, VOLUME 46

INSTITUTE OF MATHEMATICS

POLISH ACADEMY OF SCIENCES

WARSZAWA 1999

\title{
HELENA RASIOWA, 1917-1994 ${ }^{1}$
}

\author{
WIKTOR BARTOL \\ Institute of Mathematics, Warsaw University \\ Banacha 2, 02-097 Warszawa, Poland \\ E-mail: bartol@mimuw.edu.pl \\ EWA OREOWSKA \\ Institute of Telecommunications \\ Szachowa 1, 04-894 Warszawa, Poland \\ E-mail: orlowska@itl.waw.pl \\ ANDRZEJ SKOWRON \\ Institute of Mathematics, Warsaw University \\ Banacha 2, 02-097 Warszawa, Poland \\ E-mail: skowron@mimuw.edu.pl
}

1. Elements of a biography. Helena Rasiowa, mathematician and logician, passed away on August 9, 1994. Her influence on the shape of mathematical logic can hardly be overestimated.

She was born in Vienna on June 20, 1917 to very patriotic Polish parents. As soon as Poland had regained its independence in 1918 after more than a century of partitioned stateless existence, the whole family settled in Warsaw. Helena's father was a high-level railway specialist; his knowledge and experience in the field led him to assume very important positions in the railway administration. The girl, her parents' only child, had good conditions to grow up physically and mentally. And, indeed, she exhibited many different skills and interests, varying from music, which she was learning at a music school simultaneously with her normal studies in a secondary school, to business management, which she studied for more than a semester after completing her secondary education. But finally the most important of her interests, as the future was to prove, took the lead.

In 1938, the time was not very propitious for entering a university. Even if not many in Europe were convinced that war was inevitable, the next year was to prove how mistaken

\footnotetext{
${ }^{1}$ Reprinted by courtesy from Modern Logic, vol. 5, no. 3 (July 1995), pp. 231-247; (C) Modern Logic Publishing.
} 
those of the majority were. Rasiowa had to interrupt her studies, for no legal education was possible in Poland after 1939. Many people fled the country or at least they fled the big towns, more subject to German bombardments and terror. So did the Raś family, also because of the fact that most high-ranking administrative officials and members of the government were being evacuated towards Romania. The Raśs spent a year in Lvov. After Soviet invasion in September 1939 the town was taken over by the Soviet Union. The life of many Poles became endangered, so eventually the father decided to return to Warsaw.

Life was very restricted in Poland during the Nazi occupation. Nevertheless, there were enough courageous people to organize an underground life, not only for armed conspiracy against the Nazis, but also for the development of all the areas of a nation's life which are vital for its survival, education and, in particular, higher education among them. Thus Helena Rasiowa followed her studies in mathematics, risking her life, as did everybody who dared to conspire during that dark period.

Polish mathematics acquired particular strength in the pre-war years, mainly after the emergence of the Polish School of Mathematics in 1921. The names of Stefan Mazurkiewicz and Wacław Sierpiński, who were in Warsaw, or those of Stefan Banach and Hugo Steinhaus, who were in Lvov, were well known to mathematicians all over the world. One of the branches which became important at that time besides functional analysis, set theory and topology, was logic, with researchers such as Jan Eukasiewicz, Stanisław Leśniewski, Kazimierz Ajdukiewicz, Alfred Tarski and others.

Rasiowa became strongly influenced by Polish logicians. Still in conspiracy, she wrote her Master's thesis under the supervision of Jan Łukasiewicz and Bolesław Sobociński. History, however, turned against her once more. In 1944, the Warsaw Uprising broke out and, in consequence, Warsaw was almost completely destroyed, not only because of warfare, but also because of the systematic destruction which followed the uprising after it had been put down. Rasiowa's thesis was burned, together with the whole house. She herself survived with her mother in a cellar that was covered by the ruins of a demolished building.

After the war, Polish mathematics, as all other areas of life, began to recover its institutions, its moods and its people. Many had been killed, many had died, many had left the country, but those who remained considered their duty to be the reconstruction of Polish science and universities. One of the important conditions for this reconstruction was to gather together all those who could participate in recreating mathematics. Rasiowa had in the meantime accepted a teacher's position in a secondary school. That is where she was discovered by Andrzej Mostowski and brought back to the University. She rewrote her Master's thesis in 1945 and in the next year she started her academic career as an assistant at the University of Warsaw, the institution she remained linked with for the rest of her life.

At this University she prepared and defended her Ph.D. thesis in 1950 (under the guidance of Prof. Andrzej Mostowski). The title of the thesis was Algebraic treatment of the functional calculi of Lewis and Heyting and it pointed to the main field of her future research: algebraic methods in logic. In 1956 she made her second academic de- 
gree (equivalent to habilitation today) in the Institute of Mathematics of the Polish Academy of Sciences, where between 1954 and 1957 she held the post of Associate Professor jointly with an analogous position at the University, becoming Professor in 1957 and subsequently Full Professor in 1967. For the degree she submitted two papers: "Algebraic models of axiomatic theories" and "Constructive theories", which together formed a thesis named Algebraic models of elementary theories and their applications.

Her interests were not limited to pure research. Always ready to cooperate with others and aware of the importance of a strong mathematical community, she participated in many forms of this community's activities. Since 1964, and until her retirement in 1993, she headed the section of Foundations of Mathematics and later of Mathematical Logic after its creation in 1970. For more than 15 years she was Dean of the Faculty of Mathematics, Computer Science and Mechanics (1958-1960, 1962-1966, 1968-1978). Strongly attached to the Polish Mathematical Society, she was its Secretary (1955-1957) and then Vice-President (1958-1959); in the Warsaw division of the Society she was elected President twice (1957-1959 and 1963-1965). In the Association for Symbolic Logic she was a Council member (1958-1960) and a member of the Executive Committee for European Affairs (1972-1977). She also was Alternate Assessor (1972-1975) and Assessor (1975-1979) in the Division of Logic, Methodology and Philosophy of Science of the International Union of History and Philosophy of Sciences. On the other hand, she contributed to the development of mathematics in Poland, both as a member of the Committee on Mathematics of the Polish Academy of Sciences since 1961 until her very last days, and as a member, and for 20 years Chairperson, of the Group on Education and Research in Mathematics of the Ministry of Science and Higher Education. Since 1972 she was on the Scientific Council of the Institute of Computer Science of the Polish Academy of Sciences, guiding its works as Chairperson in 1972-1983. Last but not least, in the recent years she greatly contributed to the foundation of the Polish Society of Logic and Philosophy of Science.

No description of Rasiowa's activities would be complete without a mention of her deep involvement in the development of the research journals to which she was attached. The most cherished by her, Fundamenta Informaticae (FI), was established in 1977, mostly due to her efforts, and she was its Editor-in-Chief until her death. Even when her illness began to take the better of her, she never ceased to control the preparation of the consecutive issues of the journal. In particular, she acted as Editor of a special anniversary issue commemorating the publication of the 20th volume of FI in 1994. Moreover, making once more proof of her inexhaustible energy, she was an active Collecting Editor with Studia Logica (since 1974) and Associate Editor with the Journal of Approximate Reasoning since 1986

Professor Rasiowa educated generations of students and researchers; in particular, she supervised over 20 Ph.D. theses. Her lectures were known all over the world. She was visiting professor at 14 universities, ranging from Bahia Blanca in Argentina to Moscow in the Soviet Union, passing through Campinas in Brasil, UNAM [Universidad Nacional de Mexico] in Mexico, Rome in Italy and Oxford University in England. In the USA she was hosted by universities such as Princeton, University of Chicago, University of 
California at Berkeley, and the University of North Carolina at Charlotte. Moreover, she gave invited lectures at 46 universities and research establishments abroad, in some of them more than once.

She contributed to mathematical literature with three important books and more than 100 publications. The topics covered by her work include proof theory and deductive logic, algebraic methods in logic and algebras related to logics, classical and nonclassical logics, algorithmic and approximation logics, artificial intelligence. She worked on a new monograph to her very last days. The intended title was Algebraic Analysis of NonClassical First Order Logics.

2. Algebraic logic. The study of the relationship between logic and algebra, originated by the work of George Boole and continued by A. Lindenbaum, A. Tarski, M. H. Stone, R. McKinsey, A. Mostowski and L. Henkin - to mention only a few was the main research subject of Helena Rasiowa. One of the crucial moments in the development of algebraic study of logic was the introduction of Lindenbaum's and Tarski's method for treating equivalence classes of formulas as elements of an abstract algebraic system. This provided a link between theories based on classical logic and Boolean algebras. An analogous correspondence between intuitionistic logic and pseudo-complemented lattices was established by Stone and Tarski, while the application of algebraic methods to modal logics was originated by McKinsey and Tarski (1944-1948). Another important idea leading to the emergence of the field of algebraic logic was the treatment of formulas as algebraic functions in certain algebras, initiated by Eukasiewicz and Post with their generalization of truth tables.

Helena Rasiowa became very active in these areas in the early fifties. Her research work on algebraic logic was aimed at finding a precise description for the mathematical structure of formalized logical systems. Her early papers contain several examples of algebras associated with logical systems as well as algebraic proofs of some of their properties. Jointly with Roman Sikorski she presented the first algebraic proof of the Gödel completeness theorem for classical predicate logic ([4]). Next, she algebraically proved analogous theorems for intuitionistic and modal logics ([5]). In the papers $[9,13,14,16$, $18,21,22,23,24,25,26]$ she turned to other nonclassical logics, applying with success the algebraic tools she had developed. All these investigations led her to a synthesis of the results hitherto obtained; she developed a general framework for an algebraic presentation of propositional and first order logics. In particular, she established elegant formal techniques for associating classes of algebras with logical systems and for providing their algebraic semantics. In the following, we shall briefly outline the basic elements of her method for an algebraization of logics.

Rasiowa's first monograph The Mathematics of Metamathematics [31], written jointly with R. Sikorski, contains a comprehensive survey of algebraic theories of logical calculi. Algebraization is applied to classical, intuitionistic, modal and positive logics. The book focuses on metalogical theorems on the predicate calculi of these logics and on an investigation of elementary theories based on them. The main idea underlying the concept of associating algebraic systems with logical calculi is the following: Let $L$ be a first order 
language such that $V$ is its set of individual variables, $\vee, \wedge, \rightarrow$ are the binary propositional connectives of $L, \neg$ is a unary propositional connective, and $\exists$ and $\forall$ are the quantifiers of $L$. Let $(A, \cup, \cap, \rightarrow,-, \cup, \cap)$ be a complete algebra such that $\cup, \cap$, and $\rightarrow$ are binary operations, - is a unary operation and $\bigcup$ and $\bigcap$ are infinitary operations the common domain of which is the class of all nonempty subsets of $A$. By a realization of the language $L$ in a nonempty set $J$ and in the algebra $A$ we mean any mapping $R$ which assigns a function $f_{R}: J^{V} \longrightarrow J$ to each function symbol $f$ of $L$ and a function $P_{R}: J^{V} \longrightarrow A$ to any predicate symbol $P$ of $L$. The realization $R$ is then extended to all the terms and all the formulas of $L$. Let $v \in J^{V}$ be a valuation of individual variables in a set $J$. Then we define:

$$
\begin{aligned}
& x_{R}(v)=v(x) \text { for any individual variable } x, \\
& f\left(t_{1}, \ldots, t_{m}\right)_{R}(v)=f_{R}\left(t_{1 R}(v), \ldots, t_{m R}(v)\right), \\
& P\left(t_{1}, \ldots, t_{n}\right)_{R}(v)=P_{R}\left(t_{1 R}(v), \ldots, t_{n R}(v)\right), \\
& (F \vee G)_{R}(v)=F_{R}(v) \cup G_{R}(v), \\
& (F \wedge G)_{R}(v)=F_{R}(v) \cap G_{R}(v), \\
& (F \rightarrow G)_{R}(v)=F_{R}(v) \rightarrow G_{R}(v), \\
& (\neg F)_{R}(v)=-F_{R}(v), \\
& (\exists x F)_{R}(v)=\bigcup\left\{F_{R}\left(v_{j}\right): j \in J\right\}, \text { where } v_{j} \in J^{V} \text { and } v_{j}(x)=j, \\
& v_{j}(y)=v(y) \text { for all } y \neq x, \\
& (\forall x F)_{R}(v)=\bigcap\left\{F_{R}\left(v_{j}\right): j \in J\right\}, \text { where } v_{j} \in J^{V} \text { is as above. }
\end{aligned}
$$

The algebraic semantics of the classical predicate logic is determined by the class of realizations of the language $L$ in Boolean algebras. We say that a formula is true in a realization $R$ whenever $F_{R}(v)=1$ for every valuation $v$, where 1 is the unit element of the underlying Boolean algebra. A formula $F$ is valid in the classical predicate logic if and only if $F$ is true in all realizations in any Boolean algebra. Similarly, the semantics of intuitionistic logic is given by realizations in Heyting algebras, positive first order logic is associated with realizations in the class of relatively pseduocomplemented lattices. Modal logic, also considered in the book, is semantically determined by the class of realizations in what is known as topological Boolean algebras, i.e. Boolean algebras endowed with a unary operation behaving like an interior operator.

In the next monograph, An Algebraic Approach to Non-classical Logics([49]) Helena Rasiowa develops a general algebraization theory for propositional logical systems. Within the framework of this theory she presents algebraizations of a number of nonclassical logics such as: classical and positive implicative logics, logics weaker than positive implicative logic, minimal logic, positive logic with semi-negation, constructive logic with strong negation, and many-valued Post logics. The fundamental idea behind algebraization is the following: Let $S=(L, C)$ be a propositional logic, where $L$ is a propositional language that includes implication as a binary connective and $C$ is a consequence operation determined by the axioms and inference rules. As usual, for a set $X$ of formulas we denote by $C(X)$ the least set of formulas which contains the axioms and the set $X$ and is closed with respect 
to the inference rules. In particular, $C(\emptyset)$ is the set of all the theorems of $S$. An algebra associated with $S$ is any algebra of a type similar to that of the algebra of formulas of $S$ and endowed with a distinguished element 1. Elements of such an algebra are interpreted as truth values, whereas 1 represents the value true. Let $V$ be the set of propositional variables of $L$. By a valuation in an algebra $A$ associated with $S$ we mean any mapping $v \in A^{V}$. Every formula $F$ of the language $L$ induces a mapping $F_{A}: A^{V} \longrightarrow A$ defined as follows:

$$
\begin{aligned}
& p_{A}(v)=v(p) \text { for any propositional variable } p, \\
& (\# F)_{A}(v)=\#\left(F_{A}(v)\right) \text { for every unary propositional connective \# of } L, \\
& (F \# G)_{A}(v)=F_{A}(v) \# G_{A}(v) \text { for every binary connective \# of } L .
\end{aligned}
$$

A formula $F$ is said to be true in $A$ if and only if $F_{A}(v)=1$ for every $v \in A^{V}$.

Any propositional logic $S$ determines thus a class of $S$-algebras, where an $S$-algebra is an algebra $A$ associated with $S$ such that for every formula $F \in C(\emptyset)$ we have $F_{A}(v)=1$ for every $v \in A^{V}$. The completeness theorem states that if $S$ is consistent, then the set $C(\emptyset)$ is equal to the set of all formulas which are true in each $S$-algebra.

Helena Rasiowa paid very much attention to many-valued Post logics. She introduced several generalizations of the standard $m$-valued Post logics; she considered the propositional and predicate versions of $\omega^{+}$-valued Post logics and used them in her reasoning on programs. The following section describes some of these applications in more detail.

3. Mathematical foundations of computer science. Helena Rasiowa greatly contributed to the development of research in Poland on applications of logical methods in the foundations of computer science. She was one of the first to realize the great importance of mathematical logic for computer science - and at the same time she clearly saw the significance of computer science for the development of logic itself. In the last 20 years of her scientific activity she focused her efforts on the realization of this main idea through papers, seminars and research projects. Many of her students and collaborators who attended her lectures or seminars, those who wrote their Ph.D. theses under her supervision, are now continuing the work she initiated. There remains no doubt today that she was right in her appreciation of the significance of the field. Among the authors of important research results on logical and algebraic methods in computer science, the names of her students can be found quite often. Moreover, some of these important results have appeared in a journal which would not have existed without her dedication and to which she had been Editor-in-Chief for many years, i.e. Fundamenta Informaticae.

The form of this short article makes difficult a complete presentation of her achievements in the field of applications of logical and algebraic methods in computer science. She is the author of more than 30 papers, two lecture notes ([63], [72]) and an unfinished monograph in which she relates algebraic methods of nonclassical logics with applications in the foundations of computer science. She was able to write eight chapters before she was taken to hospital. 
Her contribution to theoretical computer science stems from her conviction that there are deep relations between methods of algebra and logic on one side and essential problems of foundations of computer science on the other. Among these problems she clearly distinguished inference methods characteristic of computer science and its applications. This conviction of hers had been supported by her results on many-valued and nonclassical logics, especially on applications of various generalizations of Post algebras to logics of programs and approximation logics.

Her investigations on logic and algebraic methods in computer science can be divided into two main streams. The first includes many-valued algorithmic logics and their applications to investigation of programs ([42-44], [51], [53-64], [69-72]), while the second is concerned with approximation logics in their relation with generalizations of Post algebras $([73-97])$.

In a series of papers on algorithmic logic, Rasiowa presents the results of her research on generalizations of classical algorithmic logic introduced by A. Salwicki to complex algorithms, which include programs with stacks or coroutines, programs with recursive coroutines, as well as procedures and recursive procedures. In these papers she makes intensive use of Post algebras of order $\omega^{+}$, which she introduced and studied in several publications, some of them written jointly with George Epstein. Rasiowa was particularly interested in axiomatizations of algorithmic logics corresponding to different classes of programs, and this problem is represented in her papers belonging to this stream of research. The lecture notes [72], based on her lectures at the Istituto per le Aplicazioni del Calcolo, reflect her search for a homogeneous approach to a wide class of logics of complex programs, an approach which would be general enough to yield known logics as particular cases. The first lecture notes $([63])$, formed by lectures delivered at Simon Fraser University, correspond to the same point of view.

In 1984 Helena Rasiowa initiated intensive investigations on methods of inference under incomplete information, which she called approximate reasoning. At present, approximation logics are becoming one of the central topics of research in artificial intelligence, and among the algebraic tools used in this research an important role is assigned to those created and developed by Rasiowa. They include generalizations of Post algebras, among them semi-Post algebras $([84])$ and the so-called plain semi-Post algebras ([89]), which served as a basis for the construction of logics of approximate reasoning. During this period, Rasiowa worked with several mathematicians, such as George Epstein (University of Charlotte, North Carolina), Wiktor Marek (State University of Kentucky), Nguyen Cat-Ho (Vietnam), and Andrzej Skowron (Warsaw University).

The papers [73-97] correspond to the period between 1984 and 1994. In [74] first order approximation logics are constructed. They are based on approximation operators in the sense of Z. Pawlak, which are applied to sets and relations defined by first order formulas. In [75] these logics were extended to the case of a chain of equivalence relations which determine lower and upper approximations.

The paper [84] introduces a generalization of Post algebras, called semi-Post lattices (algebras). The primitive Post constants are elements of a poset rather than of a chain, complete lattice or connected semilattice as it had been usual in generalized Post algebras 
(e.g. in papers by Dwinger, Traczyk, Speed, Rasiowa, Cat-Ho). Several characterizations of sublattices of a reduct of a semi-Post algebra which are semi-Post subalgebras are given, as well as different characterizations of semi-Post homomorphisms. These make use of a theorem stating that every semi-Post algebra is a semi-Post product of generalized Post algebras in the sense of Cat-Ho.

In [82] Rasiowa presents an algebraic approach to approximate reasoning, based on modified information systems of Dana Scott. Semi-Post algebras built over Scott's information systems are used as tools for an analysis of the properties of approximate reasonings.

Approximate reasonings are also treated in [76], [77], where they are based on a decreasing sequence of equivalence relations, which define a sequence of closure operators. The main result consists in a characterization of those sets $X$ which are intersections of the family of all closures.

In [83] methods of approximate reasoning related to a selection strategy are studied. Here again, semi-Post algebras are used as a tool for investigations. The properties of approximate deductions are expressed in a first order logic introduced in the paper. Its semantics is defined via semi-Post algebras and a representation theorem.

The paper [86] deals with approximation logics of different types $T$, where $T$ is a well-founded poset. Such logics were introduced by Rasiowa in [83] and they stem from the idea that a set of objects to be recognized in a process of approximate reasoning is approximated by a family of covering sets and by their intersection, and it relies on the notion of rough sets in the sense of $Z$. Pawlak. The approach is axiomatic; a completeness theorem is proved algebraically, using plain semi-Post algebras. Such algebras had first appeared in literature in [89]. Their importance within the class of all semi-Post algebras is due to their simplicity and strong analogies with Post algebras, but also due to their importance in the investigation of approximation logics. The main result of the paper refers to the representability of these algebras. Every element is uniquely represented in a normal form.

In [88] an epistemic logic is designed which formalizes approximating reasonings performed by groups of agents who perceive reality via perception operators, which are their individual attributes, and knowledge operators, which are attributes of subsets of agents when arriving at a consensus. It is assumed that the set of agents is a poset $\mathbf{T}=(T, \leq)$ ordered with respect to the sharpness of perception and the ability to distinguish objects. An axiomatization of the logic introduced is given, and a completeness theorem is proved, together with several other metalogical theorems. This logic is free of the paradoxes which appear in other epistemic logics. The research initiated in [88] was continued in [92] and [93].

The problem of axiomatizing fuzzy sets is one of the most interesting and topical problems in the theory of these sets. In [94] Rasiowa introduces the notion of an $L T$ fuzzy set, which is a modification of $L$-fuzzy sets in the sense of Goguen (1967). This new approach was based on the theory of semi-Post algebras, which made possible the development of an axiomatic theory of algebras of $L T$-sets ([94]) and a representation theorem. $L T$-fuzzy sets are endowed with a rich structure and the classical fuzzy sets 
of L. Zadeh (1965) appear here as a particular case. The results show the numerous advantages of this approach; in particular, it leads to a solution of the axiomatization problem for $L T$-fuzzy sets. The papers [94-97] introduce and develop the new approach to fuzzy and rough sets, based on semi-Post algebras. $L T$-fuzzy logics formalize approximate reasonings applied to notions which are not totally determined.

In [90] a theory of algebras of order $\omega+\omega^{*}$ is developed and applied to a construction of an approximation logic. Post algebras of order $\omega+\omega^{*}$ are particularly interesting because of the fact that, in spite of their infinite order, they preserve more analogies with Post algebras of finite orders than any other known generalization of the latter algebras. Besides, they have proved very useful in applications to approximation logics of infinite type, allowing both lower and upper approximations of sets being recognized. The theory of Post algebras of order $\omega+\omega^{*}$ contains a set representation theorem and is used to formulate a complete axiomatization of a first order approximation logic.

These brief examples of Rasiowa's research results on approximation logics illustrate the variety and wealth of her investigations; likewise, they exhibit the relation between the important topics of today's computer science and the algebraic methods which she constantly developed for the sake of investigations in logic.

Until the very last moments of Professor Rasiowa's life we admired her youthful enthusiasm towards research, her valuable and original results, and her ability to justly appreciate the perspectives of newly arising research directions. It is not easy to accept that we shall have to proceed with our work without her.

\section{Bibliography (not complete)}

[1] Axiomatisation d'un système partiel de la théorie de la deduction, Comptes-Rendues de la Soc. de Sci. et de Lettres de Varsovie, Cl. III (1947), 22-37.

[2] Sur certaines matrices logiques, Comptes-Rendues de la Soc. Pol. de Math. 20 (1947), 402-403.

[3] Sur un certain système d'axiomes du calcul des propositions, Norsk Matematisk Tiddskrift 31 (1949), 1-3.

[4] (with R. Sikorski) A proof of the completeness theorem of Gödel, Fundamenta Mathematicae 37 (1950), 193-200.

[5] Algebraic treatment of the functional calculi of Heyting and Lewis, Fundamenta Mathematicae 38 (1951), 99-126.

[6] (with R. Sikorski) A proof of the Skolem-Löwenheim theorem, Fundamenta Mathematicae 38 (1951), 230-232.

[7] A proof of the compactness theorem for arithmetical classes, Fundamenta Mathematicae 39 (1952), 8-14.

[8] (with A. Mostowski, A. Grzegorczyk, S. Jaśkowski, J. Łoś, S. Mazur, R. Sikorski) Der gegenwärtige Stand der Grundlagenforschung in der Mathematik, Die Hauptreferate des 8. poln. Mathematikerkongresses, Warschau, Sept. 6-12, 1953 (Berlin, Deutscher Verlag der Wiss., 1954), 11-44. 
[9] (with R. Sikorski) Algebraic treatment of the notion of satisfiability, Fundamenta Mathematicae 40 (1953), 62-95.

[10] (with A. Mostowski) Geometryczna interpretacja wyrażeń rachunków funkcyjnych (Geometrical interpretation of expressions of functional calculi), Studia Logica 1 (1953), 254275.

[11] (with R. Sikorski) On satisfiability and decidability in non-classical functional calculi, Bull. Acad. Polon. de Sci., Cl. III, 1 (1953), 229-231.

[12] (with R. Sikorski) On existential theorems in non-classical functional calculi, Fundamenta Mathematicae 41 (1954), 21-28.

[13] Constructive theories, Bull. Acad. Polon. Sci., Cl. III, 2 (1954), 121-124.

[14] Algebraic models of axiomatic theories, Fundamenta Mathematicae 41 (1954), 291-310.

[15] O pewnym fragmencie implikacyjnego rachunku zdań (On a fragment of the implicational propositional calculus), Studia Logica 3 (1955), 203-226.

[16] (with R. Sikorski) An application of lattices to logic, Fundamenta Mathematicae 42 (1955), 83-100.

[17] A proof of $\epsilon$-theorems, Bull. Acad. Polon. Sci., Cl. III, 3 (1955), 299-302.

[18] (with A. Białynicki-Birula) On the representation of quasi-Boolean algebras, Bull. Acad. Polon. Sci., Cl. III, 5 (1957), 259-261.

[19] On the $\epsilon$-theorems, Fundamenta Mathematicae 43 (1956), 156-165.

[20] (with J. Łoś, A. Mostowski) A proof of Herbrand's theorem, Journ. des Math. Pures et Appl. 35 (1956), 19-24.

[21] Sur la méthode algébrique dans la méthodologie des systèmes déductifs élémentaires, Bull. Math. de la Soc. Sci. Math. Phys. de la R. P. R., 1 (49), No. 2 (1957), 223-231.

[22] (with R. Sikorski) On the isomorphisms of Lindenbaum algebras with fields of sets, Colloquium Mathematicum V (1958), 143-158.

[23] $N$-lattices and constructive logic with strong negation, Fundamenta Mathematicae 46 (1958), 61-80.

[24] (with A. Białynicki-Birula) On constructible falsity in the constructive logic with strong negation, Colloquium Mathematicum VI (1958), 287-310.

[25] Algebraische Charakterisierung der intuitionistischen Logik mit starker Negation, in: Constructivity in Mathematics, Studies in Logic and the Foundations of Mathematics (Amsterdam, North-Holland, 1959), 234-240.

[26] (with R. Sikorski) Formalisierte intuitionistische elementäre Theorien, in: Constructivity in Mathematics, Studies in Logic and the Foundations of Mathematics (Amsterdam, North-Holland, 1959), 241-249.

[27] (with R. Sikorski) On the Gentzen theorem, Fundamenta Mathematicae 48 (1960), 57-69.

[28] (with J. Łoś, A. Mostowski) Addition au travail 'A proof of Herbrand's theorem', Journ. des Math. Pures et Appl. 40 (1961), 129-134.

[29] On modal theories, Acta Philosophica Fennica, Fasc. XVI (1963), 201-214.

[30] (edited by H. Rasiowa and A. Mostowski) Computable analysis, Stanistaw Mazur, Rozprawy Matematyczne, 33, 1963, 110 pp.

[31] (with R. Sikorski) The mathematics of metamathematics, Monografie Matematyczne 41, PWN, 1963, 519 pp.; 2nd edition 1968, 3rd edition 1970.

[32] Logika matematyczna (Mathematical Logic), in: Encyklopedia "Przyroda i technika", Wiedza Powszechna 1964, pp. 610-615; 2nd edition 1967, pp. 655-659.

[33] A generalization of a formalized theory of fields of sets on non-classical logics, Rozprawy Matematyczne 42 (1964), 29 pp. 
[34] On non-classical calculi of classes, Coll. on the Foundations of Mathematics, Mathematical Machines and their Applications, Tihany, Sept. 11-15, 1962, (Budapest, Akademiai Kiado, 1965), 53-55.

[35] Wstęp do Logiki Matematycznej i Teorii Mnogości (Introduction to Mathematical Logic and Set Theory), Bibl. Kursów Zastosowań Matematyki, Inst. Matem. PAN, 1966, 166 pp.

[36] O wyktadzie Wstȩp do Matematyki (On the course 'Introduction to Mathematics'), Wiadomości Matematyczne IX (1967), 240-243.

[37] Wstęp do matematyki wspótczesnej (Introduction to modern mathematics), Bibl. Matematyczna 30, PWN, 1968, 302 pp.; 2nd edition 1969, 3rd edition 1971, 4th edition 1974 5th edition 1975, 6th edition 1977, 7th edition 1979, 8th edition 1984.

[38] Introduction to modern mathematics (in Bulgarian), Nauka i Iskustvo, Sofia, 1972.

[39] A theorem on the existence of prime filters in Post algebras and the completeness theorem for some many valued predicate calculi, Bull. Acad. Polon. Sci., Série Sci. Math. Astr. Phys. 17 (1969), 347-354.

[40] Ultraproducts of m-valued models and a generalization of the Löwenheim-Skolem-GödelMalcev theorem for theories based on m-valued logics, Bull. Acad. Polon. Sci., Série Sci. Math. Astr. Phys. 18 (1970), 415-420.

[41] The Craig interpolation theorem for m-valued predicate calculi, Bull. Acad. Polon. Sci., Série Sci. Math. Astr. Phys. 20 (1972), 141-146.

[42] On logical structure of programs, Bull. Acad. Polon. Sci., Série Sci. Math. Astr. Phys. 20 (1972), 319-324.

[43] On algorithmic logic, Abstracts of 1971 Meeting on Computational Linguistics, Debrecen, Yugoslavia, Sept. 4-7, 1971.

[44] On m-valued predicate calculi, Abstracts IV International Congress for Logic, Methodology and Philosophy of Science, Bucarest, Romania, August 29 - Sept. 4, 1971, Vol. 44.

[45] (with R. Sikorski) The mathematics of metamathematics (in Russian), Izdatelstvo Nauka, Moscow, 1972.

[46] Roman Sikorski, Nauka Polska 20, zesz. 4 (1972), 70-75.

[47] Introduction to modern mathematics, North-Holland and American Elsevier, 1973, 326 pp.

[48] Introduction to modern mathematics, PWN and North-Holland, 1973, 326 pp.

[49] An algebraic approach to non-classical logics, Studies in Logic and the Foundations of mathematics, Vol. 78, North-Holland 1974, 403 pp.

[50] Post algebras as a semantic foundation of m-valued logics, The Mathematical Association of America Studies in Mathematics, Vol. 9, 1974, 92-142.

[51] On a logical structure of programs, Proc. Intern. Symp. and Summer School on Math. Foundations of Comp. Sci., Jabłonna, August 21-26, 1972, CC PAS Reports.

[52] On generalized Post algebras of order $\omega^{+}$and $\omega^{+}$-valued predicate calculi, Bull. Acad. Polon. Sci., Série Sci. Math. Astr. Phys. 21 (1973), 209-219.

[53] On logical structure of mix-valued programs and the $\omega^{+}$valued algorithmic logic, Bull. Acad. Polon. Sci., Série Sci. Math. Astr. Phys. 21 (1973), 451-458.

[54] Formalized $\omega^{+}$-valued algorithmic systems, Bull. Acad. Polon. Sci., Série Sci. Math. Astr. Phys. 21 (1973), 559-565.

[55] Mixed-valued predicate calculi, Studia Logica 34 (1975), 215-234.

[56] On $\omega^{+}$-valued algorithmic logic and related problems, Invited lecture, MFCS'73, High Tatra, CCPAS Reports 150, 1974.

[57] A simplified formalization of $\omega^{+}$-valued algorithmic logic (a formalized theory of programs), Bull. Acad. Polon. Sci., Série Sci. Math. Astr. Phys. 22 (1974), 595-603. 
[58] Extended $\omega^{+}$-valued algorithmic logic (a formalized theory of programs with recursive procedures), Bull. Acad. Polon. Sci., Série Sci. Math. Astr. Phys. 22 (1974), 605-610.

[59] $\omega^{+}$-valued algorithmic logic as a tool to investigate procedures, Invited lecture, MFCS'74, Warszawa-Jadwisin, Lect. Notes in Comp. Sci. 28, Proceed. MFCS'74, Springer-Verlag, 1975.

[60] Many-valued algorithmic logic, Invited lecture, Proceed. Intern. Summer Institute and Logic Colloquium, Kiel 1974, Lect. Notes in Mathem. 499, (Berlin/Heidelberg/New York, Springer-Verlag, 1975), 543-567.

[61] Multiple-valued algorithmic logic as a tool to investigate programs, Invited lecture, 1975 Intern. Symp. on Multiple-Valued Logic, Indiana Univ., Bloomington, USA, May 25-28, 1975, Proceedings, 1-3.

[62] Completeness theorem for extended algorithmic logic, Proceed. 5th Congress of Logic, Methodology and Philosophy of Sciences, London, Ontario, August 27 - Sept. 2, 1975, III, 13-15.

[63] Algorithmic logic, Lecture Notes, Lectures delivered at Simon Fraser Univ., May-July 1975, ICS PAS Reports 281 (Warsaw), 1977, 206 pp.

[64] (with L. Banachowski, A. Kreczmar, G. Mirkowska, A. Salwicki) An introduction to algorithmic logic, Banach Center Publications, Vol. 2, (Warszawa, PWN, 1977), 7-99.

[65] Andrzej Mostowski (1913-1975), Nauka Polska 9-10 (1976), 233-237.

[66] Andrzej Mostowski, The review of the Polish Academy of Science, 1976, No. 4.

[67] A tribute to Andrzej Mostowski, Invited paper, in R. O. Gandy and J. M. E. Hyland (editors), Logic Colloquium'76 (Amsterdam/London, North-Holland, 1977), 139-144.

[68] In memory of Andrzej Mostowski, Studia Logica 36, No. 1-2 (1977), 1-3.

[69] Many-valued algorithmic logic as a tool to investigate programs, in: G. Epstein and J. M. Dunn (editors), Modern Uses of Multiple-Valued Logic ISMVL'75 (Dordrecht, Reidel, 1977), 77-102.

[70] Algorithmic logic and its extensions, a survey, Invited paper, Proceed. of the 5th Scandinavian Logic Symposium, Aalborg, January 17-19, 1979, 163-174.

[71] Algorithmic logic, multiple-valued extensions, Invited paper, Intern. Symp. on Practical and Philosophical Motivations of Non-classical Logics, Studia Logica 38 (1979), 317-335.

[72] Infinitary logic and logics of programs, Raccolta a Cura di Gianfranco Mascari, Istituto per le Aplicazioni del Calcolo, Consiglio Nazionale delle Ricerche, 1982, Rome, Italy.

[73] Topological representations of Post algebras of order $\omega^{+}$and open theories based on $\omega^{+}$. valued Post logic, Studia Logica XLIV, No. 4, 1985.

[74] (with A. Skowron) Rough concept logic, Proceed. 5th Symp. on Computation Theory, LNCS 208 (Springer-Verlag 1985), 288-297.

[75] (with A. Skowron) Approximation logic, in: Math. Methods of Specification and Synthesis of Software Systems, W. Bibel and K. P. Jantke (editors), Math. Research 31 (Berlin, Akademie-Verlag, 1985), 123-139.

[76] (with W. Marek) Approximating sets with equivalence relations, Theoretical Computer Science 48 (1986), 145-152.

[77] (with W. Marek) Approximating sets with equivalence relations, in: Proceed. ISMIS'86, Knoxville, Tenn., 1986, ACM SIGART, 190-200.

[78] Rough concepts and multiple-valued logic, Proceed. 16th ISMVL'86, Blacksburg, VA, 1986 (IEEE Computer Society Press), 282-288.

[79] (with G. Epstein) P-algebraic extensions of Post algebras of order $\omega^{+}$, in: Proceed. ISMVL'86, Blacksburg, VA, 1986 (IEEE Computer Society Press), 4-7. 
[80] Logic approximating sequences of sets, in: Proceed. Advanced Intern. School and Symp. on Math. Logic and its Applications, honorably dedicated to 80th anniversary of Kurt Gödel, (New York, Plenum Press, 1987), 167-186.

[81] (with W. Marek) Gradual approximating sets by means of equivalence relations, Bull. Pol. Acad. Sci., Math. 35, No. 3-4 (1987), 233-238.

[82] (with G. Epstein) Approximation reasoning and Scott's information systems, in: Z. Raś and M. Zemankova (editors), Methodologies for Intelligent Systems, Proceed. 2nd ISMIS'87, Charlotte, N.C., October 14-17, 1987, (Amsterdam/New York/Oxford, NorthHolland, 1987), 33-42.

[83] An algebraic approach to some approximate reasonings, in: Proceed. 17th ISMVL'87, Boston, MA, May 24-26, 1987 (IEEE Computer Society Press), 342-347.

[84] (with Nguyen Cat Ho) Semi-Post algebras, Studia Logica 46, No. 2 (1987), 147-158.

[85] (with Nguyen Cat Ho) Subalgebras and homomorphisms of semi-Post algebras, Studia Logica 46, No. 2 (1987), 159-173.

[86] Logic of approximation reasoning, Proceed. 1st Workshop on Computer Science Logic, Karlsruhe, Germany, 1987, LNCS 239, (Berlin, Springer-Verlag, 1988), 188-210.

[87] Mathematical problems in computation theory, eds. G. Mirkowska, H. Rasiowa, Proceed. 26th Semester at the Banach International Center, Warsaw, Sept. 16 - Dec. 14, 1985, Banach Center Publications 21, 1988, 597 pp.

[88] (with W. Marek) On reaching consensus by groups of intelligent agents, in: Z. W. Raś (editor), Methodologies for Intelligent Systems 4, Proceed. ISMIS'89 (Amsterdam/New York/Oxford, North-Holland, 1989), 234-243.

[89] (with Nguyen Cat Ho) Plain semi-Post algebras as a poset-based generalization of Post algebras and their representability, Studia Logica 48, No. 4, (1989).

[90] (with G. Epstein) Theory and uses of Post algebras of order $\omega+\omega^{*}$, in: Proceed. ISMVL'90, Charlotte, N. C., May 23-25, 1990, IEEE Computer Society Press, 42-47.

[91] On approximation logics, a survey, Jahrbuch 1990, Kurt Gödel Gessellschaft, Vienna, Austria, 1990, 63-87.

[92] Mechanical proof systems for logic of reaching consensus by groups of intelligent agents, Intern. Journ. of Approximate Reasoning 5, No. 4 (1991), 415-432.

[93] (with W. Marek) Mechanical proof systems for logic II, consensus programs and their processing, Journ. of Intelligent Information Systems 2, No. 2 (1992), 149-164.

[94] (with Nguyen Cat Ho) LT-fuzzy sets, Intern. Journ. on Fuzzy Sets and Systems 47, No. 3 (1992), 233-339.

[95] Towards fuzzy logic, in: L. A. Zadeh and J. Kacprzyk (editors), Fuzzy Logic for Management of Uncertainty, (New York, John Wiley \& Sons, 1992), 5-25.

[96] (with Nguyen Cat Ho) LT-fuzzy logics, in: L. A. Zadeh and J. Kacprzyk (editors), Fuzzy Logic for Management of Uncertainty, (New York, John Wiley \& Sons, 1992), 121-139.

[97] Axiomatization and completeness of uncountably valued approximation logic, Studia Logica 53, No. 1 (1994), 137-160. 